\title{
Bovine enterovirus as an oncolytic virus: Foetal calf serum facilitates its infection of human cells
}

\author{
M. SMYTH ${ }^{1}$, A. SYMONDS ${ }^{2}$, S. BRAZINOVA ${ }^{3}$ and J. MARTIN ${ }^{2}$ \\ ${ }^{1}$ Molecular Structure Solutions, MA Block, Wulfruna Street, Wolverhampton; ${ }^{2}$ Division of Biomedical Sciences, \\ School of Applied Sciences, University of Wolverhampton, Wolverhampton, WV1 1SB, UK; \\ ${ }^{3}$ Department of Pathology, University of Palacky, Oloumouc, Czech Republic
}

Received February 27, 2002; Accepted April 4, 2002

\begin{abstract}
Many viruses have been investigated for their oncolytic properties and potential use as therapeutic agents for cancer treatment. Most of these replication-competent viruses are human pathogens. We investigated the oncolytic properties of an animal virus which is non pathogenic for both its natural host and humans. Bovine enterovirus has previously been shown to exhibit a very wide tissue tropism for cell types in vitro. We compare the ability of bovine enterovirus to replicate in and to cause cytopathic effect in freshly isolated human monocytes and monocyte derived macrophages with the monocyte-like U937 tumour cell line. We also include the adherent ZR-75-1 human breast cancer cell line. We have also carried out infections of bovine enterovirus in the presence and in the absence of serum of bovine origin. Our study shows that the virus will replicate in and produce cytopathic effect in the U937 and ZR-75-1 cell types to the same extent as the cells (BHK-21) in which the virus is routinely propagated. We believe bovine enterovirus to be a worthwhile candidate for further study as an anti-tumour agent.
\end{abstract}

\section{Introduction}

Most viruses are characterised by a well defined tissue tropism constrained by the presence of specific cell surface receptors. Bovine enterovirus (BEV), a picornavirus of the genus enterovirus, is an exception. Endemic in cattle populations but non-pathogenic (1), BEV may be routinely isolated from faecal samples (2). The bovine enteroviruses have been classified into two serotypes (3), the most extensively studied of which is serotype 1 , subtype 1 . We have previously solved the crystal structure of this virus (4) and determined the structural basis for serotype specificity (5).

Correspondence to: Dr J. Martin, Division of Biomedical Sciences, School of Applied Sciences, University of Wolverhampton, Wolverhampton, WV1 1SB, UK

E-mail: j.martin@wlv.ac.uk

Key words: Bovine enterovirus, oncolytic virus, cancer
Various attempts have been made to determine the cell surface receptor for BEV, but efforts have been thwarted by the extensive range of cell types in which cytopathic effect may be demonstrated in vitro. BEV is routinely cultured in baby hamster kidney (BHK-21) cells, yet is commonly known to be readily adaptable to grow in the HeLa, human cervical carcinoma cell line, to equivalent titre. The virus has also been shown to cause no detectable pathogenic effect across a range of rodents (unpublished data). Attachment of BEV to the cellular receptor has been shown to be sensitive to neuraminidase (6). The receptors are known in the case of the major group human rhinoviruses to be ICAM-1 (7), for FMDV to be $\alpha_{v} \beta_{3}(8)$ and the coxsackieviruses which can use two different receptors: coxsackie and adenovirus receptor (CAR) and decay accelerating factor (DAF) $(9,10)$. However in the case of BEV the receptor must be a ubiquitous cell surface glycoprotein sharing structural homology with ICAM-1 and PVR as the crystal structure of BEV reveals its surface features to be similar to those viruses using these receptors.

In recent years viruses have been used for cancer therapy as alternatives to traditional methods where these are not effective. Examples of the replication-competent viruses currently being employed or investigated include vaccinia virus, reovirus, autonomous parvovirus and Newcastle disease virus (reviewed in ref. 11). Other viruses such as herpes simplex virus are being investigated in their replication deficient forms as vectors for anti-tumour agents $(12,13)$ and suicide genes (14).

We wished to further characterise and study the oncolytic properties of BEV because detailed studies have not been reported since the early 1970s when it was observed that BEV could replicate in a variety of normal and tumour cells $(15,16)$. Furthermore it has been shown that treatment with BEV could cause regression of solid and ascites tumours in rodents (17).

We examined and characterised the ability of BEV to successfully infect and produce cytopathic effect in human cells. We have chosen to investigate the monocyte-like U937 tumour cell line in order to facilitate a direct comparison with its corresponding normal counterpart, freshly isolated human monocytes and also monocyte-derived macrophages. To address possible differences in adherent and suspension cultures we have included the adherent ZR-75-1 human breast cancer cell line in the study. Finally, although the cells are of 
human origin they are all maintained in medium supplemented with serum of bovine origin. We therefore investigated possible effects of FCS on virus growth in human cells.

\section{Materials and methods}

Materials. Nycodenz-M was from Nycomed AS (Oslo, Norway). All other chemicals were from Sigma Chemical Company (Poole, UK).

Cell culture. BHK-21 (clone 13) hamster syrian kidney cells (ECACC, Porton Down, Salisbury, England) were routinely maintained in GMEM medium supplemented with FCS (10\%), penicillin $(50 \mathrm{IU} / \mathrm{ml})$, streptomycin $(50 \mu \mathrm{g} / \mathrm{ml})$, glutamine (300 $\mu \mathrm{g} / \mathrm{ml})$, and tryptose phosphate broth (5\%). The histiocytic lymphoma monocyte-like U937 cell line (18) and the ZR-75-1 human breast cancer cell line (19) (ECACC, Porton Down, Salisbury, England) were routinely maintained in RPMI 1640 medium supplemented with HEPES (20 mM), FCS (10\%), penicillin $(50 \mathrm{IU} / \mathrm{ml})$, streptomycin $(50 \mu \mathrm{g} / \mathrm{ml})$, and glutamine $(300 \mu \mathrm{g} / \mathrm{ml})$. Cells were grown in $5 \% \mathrm{CO}_{2}$ at $37^{\circ} \mathrm{C}$.

Preparation and culture of monocytes and monocyte-derived macrophages. Monocytes were isolated from heparinized venous blood of healthy volunteers using a combined dextran/ Nycodenz-M separation procedure (20) as detailed in Davies and Edwards (21). Monocytes ( $>95 \%$ purity) were suspended in RPMI 1640 medium supplemented with HEPES (20 mM), FCS $(10 \%)$, penicillin $(50 \mathrm{IU} / \mathrm{ml})$, streptomycin $(50 \mu \mathrm{g} / \mathrm{ml})$ and glutamine $(300 \mu \mathrm{g} / \mathrm{ml})$. Cells were enumerated using a haemocytometer slide. Monocytes $\left(8 \times 10^{4}\right)$ were plated into microtitre plates and cultured at $37^{\circ} \mathrm{C}$. Following 6 days in vitro they are then referred to as monocyte-derived macrophages. Cell viability (trypan blue exclusion) was $>98 \%$ throughout the period of culture.

Virus maintainance. Bovine enterovirus type 1 (ATCC, Rockville, MD, USA) was routinely propagated in BHK-21 cells. Medium was removed from confluent BHK-21 cell monolayers and the cell sheet rinsed with PBS. Previous virus harvest was added $1 \mathrm{ml}$ per $175 \mathrm{~cm}^{2}$ cell area. The inoculum was incubated on the cell sheet for $30 \mathrm{~min}$ at $37^{\circ} \mathrm{C}$ with gentle rocking to allow optimum distribution. The monolayer was covered with serum-free medium and incubated for $16 \mathrm{~h}$ at $37^{\circ} \mathrm{C}$. Virus was harvested and stored at $-20^{\circ} \mathrm{C}$.

Growth of virus in human cells. BEV was added to freshly isolated monocytes, monocyte-derived macrophages, U937 cells or ZR-75-1 cells to give a moi of 1.5 . Following $16 \mathrm{~h}$ incubation at $37^{\circ} \mathrm{C}$, cells were subjected to a freeze/thaw cycle and spun at $2000 \mathrm{rpm}$ for $4 \mathrm{~min}$. The supernatant was stored at $-20^{\circ} \mathrm{C}$ for later titration.

Virus titration. BHK-21 cells were grown until confluent in 24-well culture plates. A 10-fold dilution series of each virus sample to be titrated was made in serum-free medium and $200 \mu \mathrm{l}$ of each dilution was inoculated onto each monolayer in duplicate. Virus was adsorbed at $37^{\circ} \mathrm{C}$ for $30 \mathrm{~min}$ with rocking. The inoculum was removed, the cells washed with PBS and overlaid with $1 \mathrm{ml}$ of agar prepared as follows: a $1.5 \%(\mathrm{w} / \mathrm{v})$ solution of agar Noble was autoclaved, cooled to $45^{\circ} \mathrm{C}$ and an equal volume of double strength serum-free medium. Overlaid monolayers were incubated at $37^{\circ} \mathrm{C}$ for 3 days. One $\mathrm{ml}$ of cell fixative and stain $(20 \% \mathrm{v} / \mathrm{v}$ ethanol, $10 \% \mathrm{v} / \mathrm{v}$ formalin and $0.7 \% \mathrm{v} / \mathrm{v} 0.25 \mathrm{M} \mathrm{KOH}$ in water) was added and allowed to diffuse through the agar for $2 \mathrm{~h}$ before carefully removing the agar. Plaques were counted and the virus titre expressed as plaque forming units per $\mathrm{ml}(\mathrm{pfu} / \mathrm{ml})$.

\section{Results}

Normal in vitro infectivity. Bovine enterovirus type 1 is routinely maintained in BHK-21 cells. Fresh virus seed from the ATCC stock, stored at $-70^{\circ} \mathrm{C}$, reproducibly grows to a titre in the range $2 \times 10^{8}-2.5 \times 10^{8} \mathrm{pfu} / \mathrm{ml}$. Repeated passage followed by storage of the virus harvest at $-20^{\circ} \mathrm{C}$ causes this titre to fall by approximately two logarithmic units (unpublished). Cytopathic effect in fibroblastic cells is observed within $8 \mathrm{~h}$ post-infection as rounding up of the cells and loss of adherence. In addition, the cytoplasm becomes distinctly granular in appearance as viewed using phase contrast microscopy. When infected at moi of 1.5, all cells show this cytopathic effect after the second round of infection at $16 \mathrm{~h}$. Using this information and previous discontinued reports that BEV exhibits oncolytic properties $(15,16)$ we wished to determine, characterise and quantify this effect in human cells.

Infectivity in human cells cultured in bovine serum. To investigate possible oncolytic properties of BEV in human cells we infected freshly isolated human monocytes, monocytederived macrophages, the U937 histiocytic lymphoma monocyte-like, and ZR-75-1 human breast cancer cell lines, with the virus. Each infection was carried out at moi of 1.5 in the presence of FCS. Observation of the cells was carried out at hourly intervals in order that the onset and extent of any cytopathic effect could be noted. Medium containing any progeny virus was harvested at $16 \mathrm{~h}$ post-infection and titrated by plaque assay on BHK-21 cells also in the presence of FCS.

Virus infection was detected by the onset of cytopathic effect in the U937 cells and the ZR-75-1 cells at between 6 and $7 \mathrm{~h}$ post-infection. Fig. 1 shows U937 cells prior to infection and following the onset of cytopathic effect. Fig. 2 shows the same in the case of ZR-75-1 cells. The time of this observation was the same as for BEV-infected BHK-21 cells. Cytopathic effect in human monocytes and human monocytederived macrophages as shown in Table I was slight by comparison so was only observed much later in the infection cycle. Table I also shows the results of the titration of the supernatant from each infection. Virus replicated efficiently in both human tumour cell lines, giving titres equivalent to that grown in BHK-21 cells. Virus progeny from the infection of monocyte-derived macrophages was some two orders of magnitude lower. However, growth in the freshly isolated human monocytes gave equivalent numbers of pfu per unit volume as from BHK-21 cells.

Infectivity in human cells cultured in the absence of bovine serum. As BEV is not known to produce any disease in humans it is of interest that the results in Table I demonstrate that BEV grows to an equivalent titre in freshly isolated human mono- 
A

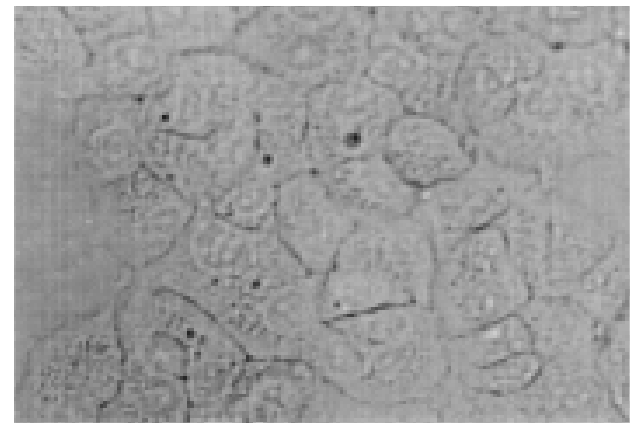

B

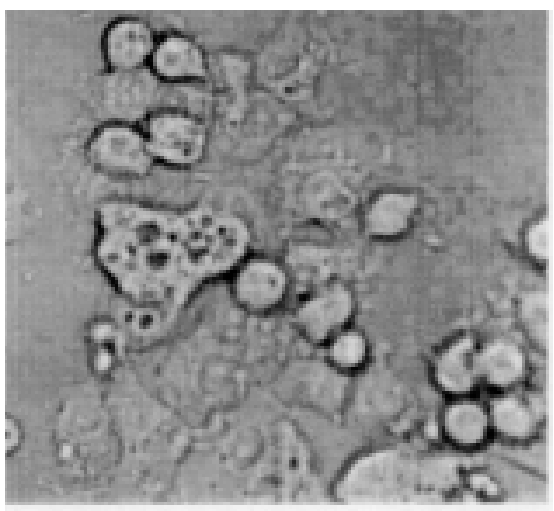

Figure 1. Effect of BEV infection on ZR-75-1 human breast cancer cells. A, appearance of ZR-75-1 cells before infection with BEV. B, cytopathic effect in ZR-75-1 cells $16 \mathrm{~h}$ post-infection with BEV.

A

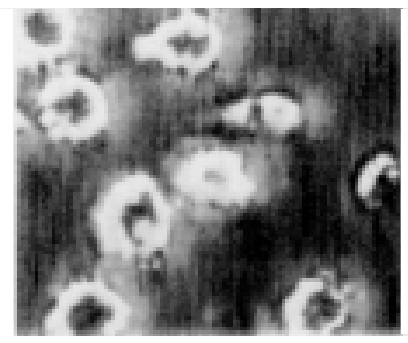

B

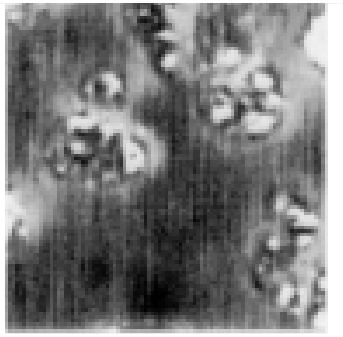

Figure 2. Effect of BEV infection on monocyte-like U937 tumour cells. A, appearance of U937 cells before infection with BEV. B, cytopathic effect in $\mathrm{U} 937$ cells $16 \mathrm{~h}$ post-infection with BEV.

cytes compared to BHK-21 cells which are routinely used for its propagation. Although the monocytes are of human origin, following their isolation from venous blood, they are cultured in medium which is supplemented with serum of bovine origin. Therefore further experiments were carried out with freshly isolated human monocytes which were cultured in the absence of FCS. In addition BHK-21 cells were infected in the absence of the bovine serum, although the cells had
Table I. Effect of BEV infection on various cell types. ${ }^{a}$

\begin{tabular}{lcc}
\hline Cell type & Cytopathic effect & Titre (pfu/ml) \\
\hline BHK-21 & +++ & $2.5 \times 10^{6}$ \\
Human monocytes & + & $2.5 \times 10^{6}$ \\
U937 & +++ & $2.5 \times 10^{6}$ \\
Human monocyte- & & \\
derived macrophages & + & $1.0 \times 10^{4}$ \\
ZR-75-1 & +++ & $2.5 \times 10^{6}$ \\
\hline
\end{tabular}

${ }^{a}$ Cytopathic effect was scored as follows, + slight, ++ moderate, +++ severe, as observed $16 \mathrm{~h}$ post infection. Titres shown are of virus harvested from $16 \mathrm{~h}$ infections of various cell types. Each experiment was carried out in the presence of FCS at a multiplicity of infection (moi) of 1.5 and all titrations were carried out by plaque assay on BHK-21 cells.

Table II. Effect of BEV infection on BHK-21 and human monocyte cells in the absence of FCS. ${ }^{\text {a }}$

\begin{tabular}{lcc}
\hline Cell type & Cytopathic effect & Titre (pfu/ml) \\
\hline BHK-21 & +++ & $2.5 \times 10^{6}$ \\
Human monocytes & + & $1.0 \times 10^{4}$ \\
\hline
\end{tabular}

${ }^{a}$ Cytopathic effect was scored as follows, + slight, +++ severe, as observed $16 \mathrm{~h}$ post infection. Titres shown are of virus harvested from $16 \mathrm{~h}$ infections of various cell types. Each experiment was carried out at a multiplicity of infection (moi) of 1.5 and all titrations were carried out by plaque assay on BHK-21 cells in the presence of FCS.

previously been cultured in FCS. It was not possible to infect monocyte-derived macrophages under the same conditions as they do not survive in vitro without FCS. In addition, U937 and ZR-75-1 cells are routinely cultured in medium containing bovine serum and therefore were not suitable for this part of the study.

The onset of cytopathic effect in the BHK-21 cells was observed as normal at 6-7 $\mathrm{h}$ post-infection while again as shown in Table II the effect of the cytopathic effect in the human monocytes was slight and not detected for 2-3 more hours. Table II shows the results of the titration from infection of BHK-21 cells and human monocytes in the absence of FCS. Virus replicated in BHK-21 cells in the absence of FCS, giving titres equivalent to that grown in BHK21 cells in the presence of FCS. However, virus progeny from the infection of monocytes in the absence of FCS was some two orders of magnitude lower in pfu per unit volume than for monocytes in the presence of FCS. All plaque assay titrations were carried out on BHK-21 cells in the presence of bovine serum. 


\section{Discussion}

BEV has a rare property among the animal viruses in that it has an extremely wide tissue tropism yet is not known to be a pathogen in any system. It is endemic in cattle populations worldwide but is unknown in humans, even those in close proximity with cattle. In this study we wished to investigate and evaluate the ability of BEV to replicate in normal human cells and their tumour counterparts.

$\mathrm{BEV}$ is routinely grown and cultured in BHK-21 cells which are in turn cultured in bovine serum. The first part of the investigation compared the cytopathic effect and titre of virus progeny of BEV infected human cells with the BHK-21 (Table I). At $16 \mathrm{~h}$ post infection the U937 and ZR-75-1 cells showed dramatic cytopathic effect (Figs. 1 and 2 respectively) comparable with that produced in BHK-21 cells. However, the human monocytes and human monocytederived macrophages showed very little cytopathic effect. When the titres of the virus progeny were determined by plaque assay on BHK-21 cells the only cell type to produce a titre lower than that normally seen from BHK-21 cells was the human monocyte-derived macrophages.

The fact that BEV can replicate in such a wide range of cell types must at least in part be due to its ability to use a receptor or range of receptors which are present on each of these cells. It has been shown in the case of FMDV that mutations in its receptor binding site, which is an RGD motif, are lethal for field isolates (22) but they are not lethal for FMDV serotypes routinely maintained in tissue culture (23). Hence as this virus apparently adapts in tissue culture to use other receptor binding sites it is possible that BEV has also adapted in such a manner. Once inside the cell BEV, along with all other enteroviruses, shuts down host protein, RNA and DNA synthesis. However, as the rapidity of the inhibition is dependent on the host cell type (24) then this may explain the variation in the titres of the virus progeny. Furthermore, such a variation may account for the late observation of onset of cytopathic effect in the monocytes and monocyte-derived macrophages.

Each of these cell types had been cultured and routinely maintained in medium supplemented with serum of bovine origin. It is possible that a factor present in the serum may mediate between the cellular receptor and the virus receptor binding site. Such accessory molecules have been identified in the attachment of other viruses. Several of the herpes viruses have been shown to use heparin sulphate as an accessory which enhances the efficiency of an internalisation receptor following initial attachment (25). In order to determine whether a component in the bovine serum was acting in such a manner it was necessary to infect cells which had never been exposed to bovine serum. Table II shows the results of freshly isolated human monocytes infected with BEV in the absence of bovine serum. The slight cytopathic effect was comparable to the same cell type in the presence of bovine serum but the titre of virus progeny was reduced by more than 100 -fold. These results indicate that there is indeed a factor present in the bovine serum which enhances infectivity. It was not possible to infect tumour cells in the same way as all such cell types in our laboratory have been routinely cultured in medium containing bovine serum. However, a previous study showed that mice bearing ascites tumour sarcoma 180 and treated with BEV showed little or no histological change other than the lysis of the tumour cells (16).

While much work remains to be carried out on BEV's oncolytic properties, clearly the results shown here together with previous discontinued studies $(15,17)$ indicate the virus to be worthy of inclusion with those viruses being investigated for cancer therapy.

\section{References}

1. Kalter SS: Animal 'orphan' enteroviruses. Bull World Health Organ 22: 319-337, 1960.

2. McFerran JB: Bovine enteroviruses. Ann N Y Acad Sci 101: 436-443, 1962.

3. Knowles NJ and Barnett ITR: A serological classification of bovine enteroviruses. Arch Virol 83: 141-155, 1985.

4. Smyth M, Tate J, Hoey E, Lyons C, Martin S and Stuart D: Implications for viral uncoating from the structure of bovine enterovirus. Nat Struct Biol 2: 224-231, 1995.

5. Smyth MS and Martin JH: Structural, biochemical and electrostatic basis of serotype specificity in bovine enteroviruses. Arch Virol 146: 347-355, 2001.

6. Stoner GD, Williams B, Kniazeff A and Shimkin MB: Effect of neuraminidase pre-treatment on the susceptibility of normal and transformed mammalian cells to bovine enterovirus 261. Nature New Biology 245: 319-321, 1973.

7. Greve JM, Davis G, Mayer AM, Forte CP, Yost SC, Marlor CW, Kamarck ME and McClelland A: The major human rhinovirus receptor is ICAM-1. Cell 56: 839-847, 1989.

8. Neff S, Sa-Carvalho D, Rieder E, Mason PW, Blystone SD, Brown EJ and Baxt B: Foot-and-mouth disease virus virulent for cattle utilises the integrin $\alpha_{\mathrm{V}} \beta_{3}$ as its receptor. J Virol 72: 3587-3594, 1998

9. Bergelson JM, Mohanty JG, Crowell RL, St. John NF, Lublin DM and Finberg RW: Coxsackievirus B3 adapted to growth in RD cells bind to decay-accelerating factor (CD55). J Virol 69: 1903-1906, 1995.

10. Bergelson JM, Cunningham JA, Droguett G, Kurt-ones EA, Krithivas A, Hong JS, Horwitz MS Crowell RL and Finberg RW: Isolation of a common receptor for coxsackie B viruses and adenoviruses 2 and 5. Science 275: 1320-1323, 1997.

11. Driever PH and Rabkin SD (eds): Replication-competent viruses for cancer therapy. In: Monographs in Virology. Vol. 22. Karger, 2001.

12. D'Angelica M, Karpoff H, Halterman M, Ellis J, Klimstra D, Edelstein D, Brownlee $\mathrm{M}$, Federoff $\mathrm{H}$ and Fong $\mathrm{Y}$ : In vivo interleukin-2 gene therapy of established tumours with herpes simplex amplicon vectors. Cancer Immunol Immunother 47: 265-271, 1999.

13. D'Angelica M, Tung C, Allen P, Halterman M, Delman K, Delohery T, Klimstra D, Brownlee M, Federoff $\mathrm{H}$ and Fong Y: Herpes simplex virus (HSV)-mediated ICAM-1 gene transfer abrogates tumorigenicity and induces anti-tumour immunity. Mol Med 5: 606-616, 1999.

14. Marconi P, Tamura M, Moriuchi S, Krisky DM, Niranjan A, Goins WF, Cohen JB and Glorioso JC: Connexin 43-enhanced suicide gene therapy using herpesviral vectors. Mol Ther 1: 71-81, 2000.

15. Sedmak GV, Taylor MW, Jun JM and Chen TT: Oncolytic effect of bovine enterovirus on mouse and human tumours. Nature New Biology 238: 7-9, 1972.

16. Hodes ME, Morgan S, Hubbard JD, Yu P-L and Lukemeyer JW: Tissue culture and animal studies with an oncolytic bovine enterovirus (Bovine Enterovirus 1). Cancer Res 33: 2408-2414, 1973.

17. Taylor MW, Cordell B, Southrada M and Prather S: Viruses as an aid to cancer therapy: regression of solid and ascites tumours in rodents after treatment with bovine enterovirus. Proc Natl Acad Sci USA 68: 836-840, 1971.

18. Sundstrom C and Nilsson K: Establishment and characterisation of a human histiocytic cell line (U937). Int J Cancer 17: 565-573, 1976.

19. Engel LW, Young NA, Tralka TS, Lippman ME, O'Brien SJ and Joyce MJ: Establishment and characterisation of three new continuous cell lines derived from human breast carcinomas. Cancer Res 38: 3352-3364, 1978. 
20. Boyum A: Separation of lymphocytes, granulocytes and monocytes from human blood using iodinated density gradient media. Methods Enzymol 108: 88-102, 1984.

21. Davies B and Edwards SW: Interactions between human monocytes and tumour cells: monocytes can either enhance or inhibit the growth and survival of K562 cells. Br J Cancer 66: 463-469, 1992.

22. Mason PW, Rieder E and Baxt B: RGD sequence of foot-andmouth disease virus is essential for infecting cells via the natural receptor but can be bypassed by an antibody-dependent enhancement pathway. Proc Natl Acad Sci USA 91: 1932-1936, 1994.
23. Martinez MA, Verdaguer N, Mateu MG and Domingo E: Evolution subverting essentiality: dispensability of the cell attachment Arg-Gly-Asp motif in multiply passaged foot-andmouth disease virus. Proc Natl Acad Sci USA 94: 6798-6802, 1997.

24. McCormick W and Penman S: Inhibition of RNA synthesis in Hela cells and L cells by Mengo virus. Virology 31: 135-141, 1967.

25. Spear PG: Entry of alphaherpeviruses into cells. Virology 4: 167-180, 1993. 